\title{
Las movilizaciones populares de los años 30, la oligarquía cristiana y la prensa francófona en el Líbano bajo el Mandato
}

\author{
Massimo Di RicCo \\ Universidad del Norte, Barranquilla (Colombia) \\ massimodiricco@gmail.com
}

Recibido: 25 de agosto de 2015

Aceptado: 16 de noviembre de 2015

\begin{abstract}
Resumen
El fermento político de la década de los años 30 en Líbano representa un importante momento histórico de consolidación nacional que llevará a la formal independencia del país con el Pacto Nacional de 1943. En esta fase, con el país bajo el Mandato francés, se distingue la presencia de una burguesía nacional que empieza a mirar con recelo las prerrogativas de las empresas francesas. La prensa francófona libanesa, directamente relacionada con la oligarquía cristiana, se vuelve en esta coyuntura una herramienta en sus manos para criticar el Mandato y atacar el adversario político en la lucha para el poder con mira al futuro Líbano independiente. El artículo destaca la estricta relación entre la agenda política y económica de una parte de las elites cristianas con las movilizaciones populares y el uso de los medios de comunicación por parte de estas oligarquías.
\end{abstract}

Palabras clave: Líbano; elites; Mandato francés; prensa y movilizaciones.

\section{Popular mobilization, Christian oligarchy and the Francophone press in Lebanon during the Mandate}

\begin{abstract}
The political upheaval in the decade of the 30s in Lebanon represents an important historical moment of national consolidation, which final outcome will be the formal independence with the National Pact of 1943. In these years, with the country under the authority of the French Mandate, it is possible to recognise the consolidation of a demanding national bourgeoisie with a growing unconformity due to the prerogatives of French companies. The Lebanese Francophone press, directly related to the two main blocks of the Christian oligarchy, became a tool in their hands in order to move their criticism towards the Mandate and against each other. The article highlights the strict relation between a part of the Christian elites agenda with these years' demonstrations, and it wants to shed light on the use of the media by these oligarchies.
\end{abstract}

Keywords: Lebanon; elites; French Mandate; press y mobilizations.

\section{Referencia normalizada}

Di Ricco, M. (2015). Las movilizaciones populares en los años 30, la oligarquía cristiana y la prensa francófono en el Líbano bajo el Mandato. Historia y Comunicación Social. Vol 20, número 2, páginas 369-389. 
Sumario 1. Introducción. 2. El Mandato francés en Líbano, la mission civilisatrice y su política económica 3. La oligarquía cristiana, la disputa por la Presidencia y la prensa francófona libanés. 4. La manifestaciones populares y las huelgas de los trabajadores en los años 30. 5. La carrera presidencial, las criticas al Mandato y las movilizaciones populares en la prensa francófona en el período 1934-1936. 6. Conclusión. 7. Referencias bibliográficas

\section{Introducción}

A través del Pacto Nacional de 1943, Riad al Solh y Bechara el Khoury sentaron las bases institucionales del Estado libanés. Aunque este fuera un pacto entre las elites de las principales comunidades para la repartición del poder sobre bases confesionales, no consiguió resolver definitivamente aquel debate alrededor de la identidad libanesa, que ha extendido hasta estos días. La época del Mandato francés, especialmente durante los años 30, reviste de vital importancia para entender este debate y poner en evidencia el papel de la prensa en la contienda.

En esta época, en Líbano confluyeron condiciones económicas y políticas, tanto a nivel local como internacional, de particular relevancia. La crisis económica mundial del 1929, aunada a otras factores, trajeron consigo el creciente descontento de las elites cristianas hacia la política económica del Mandato, siempre orientada a favorecer las empresas francesas y a unos pocos intermediarios locales. Al mismo tiempo, y solo en parte relacionado con las consecuencias de la crisis global, se asistió a un considerable fermento político de las masas de los trabajadores, con huelgas y manifestaciones, en la capital y en otras ciudades del interior como Zahle. Las autoridades del Mandato francés tuvieron que enfrentar unas protestas que se hicieron cada día más amplias y organizadas, y caracterizadas por la unión cada vez más evidente entre la población y las elites.

A estos estos factores, en esta década se suman los efectos del proceso de modernización sobre el grueso de la población y el deseo de independencia de las oligarquías locales, que empiezan a poner sus intereses sobre la máquina modernizadora francesa. La importancia de esta época se entiende por el hecho que llevó, por una parte, a los primeros tratados y negociaciones entre la potencia mandataria y las fuerzas locales, y por otra, a un primer acercamiento de las posiciones entre los artífices principales del Pacto Nacional del 1943.

Los antecedentes de este amplio fermento político se encuentran ya en la década anterior, a lo largo de los años 20, bien representados por una serie de huelgas contra la empresa de gestión de la electricidad, uno de los principales símbolos de la llamada misión civilizadora francesa. Al principio de los años 30, estos tipos de movilizaciones empezaron a asumir un componente antimandatario, y pusieron las bases para un movimiento que se puede definir como proto-nacionalista y auténticamente libanés. En el ámbito de esta segunda fase de movilizaciones, se asistió a un apoyo más incondicional a las protestas por parte de los diferentes bloques de la oligarquía financiera 
y económica local, especialmente cristiana, a través de la prensa francófona libanés, a ellos estrechamente relacionada.

En estas décadas, Beirut consolida su fama a nivel internacional, y en el mundo árabe en particular, como centro de la prensa y la industria editorial, reiterando lo que fue su rol al principio de la Nahda, la época de renacimiento cultural y del pensamiento que invistió todo el mundo árabe a lo largo del siglo XIX. Una tradición periodística que sus emigrantes exportaron tanto en países de la región como Egipto, donde fundaron los principales periódicos del país, así como en la mayoría de los países de América Latina que recibieron migrantes de origen árabe entre el final del siglo XIX y la primera parte del XX. Aunque en Líbano la mayoría de estos periódicos fueron de breve duración, entre 1918 y 1939 se publicaron más de 250 periódicos en árabe y más de 30 en francés y armenio (Ayalon, 1995: 82-91). Las nuevas potencialidades de la prensa no pasaron desapercibidas a unas elites que empezaron a fundar y utilizar estos medios en el ámbito del fermento político, también con el objetivo de divulgar su posición, en algunos casos dirigir sus críticas contra el Mandato o atacar el adversario en la contienda política, y obtener resultados políticos que se ajustaran a los intereses económicos del propio bloque (Meouchy, 2002: 67).

Después de examinar brevemente la historia del Mandato francés en Líbano, con el objetivo de resaltar su política económica y el papel en esta fase histórica de una parte de las elites cristianas, sus intereses económicos y posiciones políticas, este artículo se propone analizar la contienda entre los dos bloques principales de esta oligarquía a través del análisis de los dos periódicos libaneses de habla francesa que estaban con ellos estrechamente relacionados: L'Orient y Le Jour. Estos periódicos han sido analizados en la época que va desde el 1934, año en que se fundó uno de ellos, hasta principios de 1936, cuando se asistió a la contienda presidencial entre los representantes de los mismos periódicos, Michel Eddé y Bechara El Khoury.

El análisis de los acontecimientos de estos años desde las páginas de los dos periódicos resulta útil para destacar las posiciones de los dos bloques, respecto a las movilizaciones que se produjeron en esta época, y para entender la disputa política interna a la comunidad cristiana a la víspera de las elecciones presidenciales de 1936. Una disputa entre dos bandos que en el marco de esta investigacion no toma en consideración otros actores relevantes en esta época como el movimiento fundado por Antoun Saade, que tenía una base preponderante de miembros de la comunidad griego-ortodoxa, y que influenció fuertemente los participantes al debate alrededor del nacionalismo libanés. A través del análisis de estas, se pueden entender sus posiciones respecto al Mandato y los intereses económicos de las dos facciones, y se pueden avanzar consideraciones sobre el uso de los medios de comunicación de masa por parte de grupos políticos y económicos emergentes que intentaban hacerse con el poder en mano de los franceses.

El acercamiento a este tema, y el análisis de fuentes primarias, se debe también a una todavía escasa literatura presente sobre el Mandato francés en Líbano. A parte de los trabajos publicados en la última década por parte de algunas instituciones 
francesas, la mayoría de las obras e investigaciones al respecto se deben al esfuerzo por parte de históricos anglosajones e israelíes, que se centraron en el análisis de los fondos de los Ministerios de Relaciones Exteriores francés e inglés, respectivamente, en los archivos de Nantes y de la Oficina de Relaciones Exteriores de Londres.

La historiografía existente sobre esta época ha identificado unos cambios en la posición de la oligarquía respecto al Mandato y destacado la contienda entre los dos bloques de la burguesía, pero no ha profundizado sobre la relación de estas con las concomitantes manifestaciones populares y el uso que hicieron de ellas las elites, así como tampoco han considerado el uso de los medios de comunicación por parte de estos grupos para alcanzar objetivos políticos y económicos. Un análisis profundizado de la historiografía presente denota también la existencia de cierta confusión respecto a las posturas de la oligarquía cristiana de la época y sus objetivos.

Es importante por estas razones volver a considerar más detenidamente el fermento político que caracteriza esta época específica al principio de los años 30 , y la postura de una parte de las elites cristianas a través de la prensa cercana a sus intereses. Mientras el surgimiento y la consolidación de la prensa libanesa desde la Nahda, y su importancia para todo el mundo árabe, ha sido objeto de numerosos artículos en varios idiomas, aún falta en la historiografía sobre la época un análisis específico de los dos periódicos en francés con relación al tema de las elites y las movilizaciones populares.

Finalmente, se considera particularmente relevante un estudio más profundo de esta época porque en este momento histórico se empieza a conformar una primera forma de proto-nacionalismo auténticamente libanés que se distancia de los precedentes nacionalismos ya existentes en la región (Salibi, 1989: 37). En esta época se asiste al cambio del debate sobre el futuro Líbano y la identidad nacional en relación con el mundo árabe, una discusión que en precedencia se había centrado sobre la inclusión o exclusión del país respecto a su entorno regional. Al contrario, y como afirma Traboulsi, el enfoque en este momento histórico específico mueve su interés hacia la lucha política interna (2007: 112). Los ataques de estos años contra la presencia francesa en el territorio se deben entender en este sentido, como una herramienta útil para los diferentes actores libaneses para ensayarse contra los adversarios políticos locales, en la lucha interna para el futuro control de los recursos que estaban en las manos de la potencia colonial, pero sobre todo para promocionar su propia visión nacional.

\section{El Mandato francés en Líbano, la mission civilisatrice y su política económica}

El hilo conductor entre la presencia francés en el Levante durante el Imperio Otomano y la asignación del Mandato por parte de la Sociedad de las Naciones es representado por aquellas empresas francesas llamada por el Sultán y encargada de la modernización del imperio, especialmente en los años entre el 1895 y el 1914 (Al-Sa- 
leh, 2002:198). Con el derrumbe del Imperio Otomano y la presión de ingleses y franceses, autores de los acuerdos encubiertos de Sykes-Pycot de 1916 para repartirse la región de Medio Oriente y frustrar la aspiración nacionalista árabe, la Sociedad de las Naciones conformó dos mandatos con el Acte du Mandat del 24 de julio de 1922. Mientras los territorios de Siria y Líbano fueron asignados a los franceses, los británicos adquirieron el momentáneo control de los territorios de los actuales Irak, Jordania y de la Palestina histórica. ${ }^{1}$

El objetivo de los Mandatos, siguiendo el dictamen del Artículo 22 de la Sociedad de las Naciones, era civilizar y llevar las poblaciones de esta región a la capacidad de gobernarse por sí mismas antes de entregarle la independencia (Khoury, 2002: 77). Concomitante con el objetivo de dar forma al modelo político del nuevo Estado libanés conformado en 1920, y que había sido equipado con su primera Constitución en 1926, Francia aplicó una política económica que apuntaba a modernizar el país. Todo el proceso de modernización económica fue controlado por dos tipos de empresas francesas: las de Intérets communs y las Société concessionnaires (Traboulsi, 2007: 91-93). Las empresas de intereses comunes incluían aquellos servicios que interesaban a las dos entidades que hacían parte del Mandato, y se encargaban de la modernización de los transportes, de la comunicación y la infraestructura, tales como la administración de las aduanas, la gestión del correo, los puertos y el ferrocarril, entre otros. Las sociedades concesionarias, que se pueden definir al contrario cómo empresas a franquicia, disfrutaban del monopolio del sector público y de los principales sectores de la economía nacional. El régimen de las concesiones establecidas en 1920 había cancelado todas las disposiciones del pasado otomano, y a través de los artículos 310-315 se establecieron las nuevas normas que constituían la política económica del Mandato francés.

El proyecto francés de modernización económica iba a ser implementado a través de unos programas de planificación urbana y la inversión en infraestructura para estimular una economía de servicios, ${ }^{2}$ aunque se asistió también a un limitado desarrollo en el ámbito de la industrialización, que no era considerada una prioridad para los franceses. El poder mandatario, en lugar de estimular el desarrollo económico local, concentró sus esfuerzos en minimizar los gastos de ocupación y con escasa inversión pública. En aquellos años, se emitieron una serie de arrêtés, decretos, en relación con el sistema de concesiones, en que los principales objetivos no declarados eran los de monopolizar todas las concesiones en Siria y el Líbano en manos del Alto Comisionado, y asegurarse de que todos los recursos y riquezas del país fueran controladas por el capital extranjero. Las empresas francesas y algunas otras empresas extranjeras fueron las que más se beneficiaron durante el régimen del Mandato, por lo menos hasta el principio de los años 30 , cuando con capital y remesas de emigrantes libaneses algunas empresas sirio-libanesa consiguieron modernizarse (Daher, 2000).

Las medidas de tipo económico por parte del Mandato resultaron ser una forma para proteger los intereses de los residentes extranjeros que beneficiaban de los contratos de concesión, asegurándole protección contra cualquier competidor local o extranjero, y en evidente contraposición con lo estipulado en el artículo 11 de la 
Liga de las Naciones, que suponía un principio de igualdad económica entre los representantes de los Estados locales y las potencias mandatarias. Las imposiciones mandatarias bloquearon el establecimiento de una genuina economía nacional liderada por figuras nacionales (Chidiac, 2002), sobre todo porque al principio Francia había favorecido sus intereses económicos en el Líbano, principalmente a través de sus hombres, encargando sólo unos pocos intermediarios locales, y en contra de los intereses de buena parte de la emergente burguesía local. Como resultado de estas políticas se generó, junto con la coyuntura de la crisis económica del 1929, un considerable descontento popular y una fricción entre los intermediarios locales, la emergente burguesía comercial y financiera, y la potencia mandataria.

En este contexto, las protestas populares de esta época apuntaron implícitamente contra la política economía mandataria, aunque al mismo tiempo, la oligarquía local aprovechó la coyuntura para intentar liberarse del poder francés y apoderarse de la maquinaria de la modernización.

\section{La oligarquía cristiana, la disputa por la presidencia y la prensa francófona libanés}

Durante la época del Mandato la oligarquía comercial y financiera cristiana, que en las décadas anteriores había sido el principal referente para la potencia francés y tuvo acceso primero a los sectores más ventajosos de la economía (Traboulsi, 2014: 19), se encontraba dividida en dos bloques opuestos, que sin embargo y de ninguna forma alcanzaban representar monolíticamente la totalidad de los cristianos presente en Líbano, tanto en cuanto a elites como a los miembros de las varias confesiones cristianas. ${ }^{3}$ En este momento, las oligarquías cristianas empezaron a asumir una posición política precisa, disputándose el poder tanto dentro de la misma comunidad como por el control de las instituciones a nivel nacional, con vista a las elecciones presidenciales de enero del 1936. Esta oposición era perfectamente representada por los movimientos políticos, aún en parte informales, de al-kutla al-wataniyya, el Bloque Nacional, y al-kutla al-dusturiyya, el Bloque Constitucional, y dirigidos respectivamente por Emile Eddé y Bechara El Khoury. ${ }^{4}$ Los dos bloques tenían una visión del Líbano que se diferenciaba en varios aspectos. Eddé veía el Líbano como una patria para los cristianos, diferente del resto de Siria y los países árabes, era totalmente contrario a incorporar el futuro Líbano en el mundo árabe-islámico y era partidario de aquel Gran Líbano que se estableció en 1920 (Zamir, 1978: 232-235). Bechara El Khoury, aunque al principio de su carrera política había estado compartiendo la visión de Gran Líbano y el nacionalismo excluyente maronita, consideraba el Líbano como un país independiente construido con la colaboración entre sus componentes musulmana y cristiana, y con buenas relaciones con el restante mundo árabe. ${ }^{5}$ Bechara El Khoury estableció el Bloque Constitucional poco después de la suspensión forzada de la Constitución por parte de Francia en 1932 y pedía reformular un nuevo acuerdo con la potencia colonial y así restablecer la Constitución. 
Eddé, que en aquella época era uno de los principales intermediarios de las autoridades del Mandato, era en principio partidario de la presencia francesa. Pero se puede considerar aquí que como consecuencia de los resultados del censo del 1932, en que destacaba una emergente consistencia demográfica de las comunidades musulmanas, estaba considerando replantear tanto su visión del futuro Líbano independiente como su postura hacia el Mandato. ${ }^{6}$

La disputa entre estos dos grupos de elites urbanas aparecía evidente también a nivel intelectual, a través del enfrentamiento entre dos de las principales figuras de pensadores y teóricos del bando cristiano libanés, Charles Corm y Michel Chiha, que apoyaban respectivamente el Bloque Nacional y el Bloque Constitucional (Traboulsi, 2007: 95). Corm siempre fue partidario del Gran Líbano, separado del movimiento nacionalista árabe y sirio, y reconstruyendo la identidad libanés en los ancestros fenicios. ${ }^{7}$ Michel Chiha, un banquero y notable cristiano, veía el Líbano principalmente como un país de minorías confesionales asociadas que se posicionaba en este modo en una región a mayoría musulmana. ${ }^{8}$

Esta división intelectual también se reflejaba en los periódicos en manos de los dos adversarios políticos, y en donde los dos intelectuales a menudo publicaban sus editoriales: L'Orient y Le Jour. L'Orient fue fundado en 1923 por Gabriel Khabbaz y George Naccache, y el poeta e intelectual maronita Charles Corm entró en su órbita después de haber fundado algunos años antes la Revue Phenicienne. Le Jour salió a la calle sólo en el verano de 1934, fundado por Charles Ammoun y dirigido por Michel Chiha y Charles Helou, ${ }^{9}$ con el objetivo declarado de presentar un punto de vista político nuevo en este particular momento histórico. ${ }^{10} \mathrm{El}$ establecimiento de este nuevo diario francófono transformó el grupo de El Khoury, quien L'Orient definía con el nombre de Consortium, en un grupo bien organizado, capaz de contrarrestar el grupo ya establecido que hacía referencia a Michel Eddé, y que al contrario eran definidos por el periódico rival con el apodo de ilotes. ${ }^{11}$

La disputa entre estos dos periódicos se entiende mejor si se analiza en el contexto de la época y se considera el papel relevante jugado por la industria editorial libanesa, desde el principio de la Nahda, en todo el mundo árabe y más allá de sus confines hasta los países de América Latina (Ayalon, 1995: 24-46). En los países de America Latina los periódicos fundados por migrantes árabes fueron vehículo de un debate extremadamente importante sobre las formas del nacionalismo en el Levante (Fahrenthold, 2013: 32-34; Pacheco, 2006). Esta coyuntura, así como la creciente escolarización que implicó un crecimiento considerable de los lectores alfabetizados, hizo que en la contienda política, la prensa se transformara en una herramienta fundamental para vehicular las posiciones de los grupos en competencia, y fuera utilizada con estos fines por los miembros de las elites sociales y las nuevas profesiones (Meouchy, 2002: 66-68). No obstante el escaso conocimiento a nivel popular del francés, cabe señalar la importancia de los dos periódicos en esta lengua en el ámbito de la opinión pública libanesa, debido a la fuerte influencia de la burguesía cristiana en la política del país en este período histórico. ${ }^{12}$ 
La fuerza de esta oligarquía se debía a una serie de asociaciones y uniones matrimoniales dentro de las mismas familias, y se podía considerar como compuesta principalmente por una burguesía comercial dividida en dos ramas. ${ }^{13}$ En un primer momento, durante la Primera Guerra Mundial y los primeros años del Mandato, ambas oligarquías se habían enriquecido gracias a su cercanía a los franceses y a los europeos, como agentes en el comercio internacional, tanto en las exportaciones como en las importaciones. Pero sus diferencias e intereses, se empezaron a hacer más marcados desde los años 20. Por un lado, estaba una llamada aristocracia comercial de grandes inversores ${ }^{14}$ comerciantes locales e intermediarios de las empresas europeas, y de cierta forma aún favorecidos por el Mandato; por el otro lado una burguesía nacional, tanto comercial como financiera, cuyos miembros estaban interesados en consolidar su poder político y, en términos de sostenibilidad económica, apostaban por el desarrollo local de un mercado y una industria nacional, aunque manteniendo intereses en la economía de servicios. Mientras ambos grupos exigían aumentar sus ventajas respecto a las empresas extranjeras y hacerse con la máquina de la modernización, el grupo de la burguesía nacional pedía más explícitamente una independencia económica y política del Líbano. Este grupo estaba compuesto por industriales, empresarios, ricos emigrantes, pequeños comerciantes y propietarios de establecimientos relacionados con el sector de los servicios, y se proponían defender sus intereses que habían sido perjudicados por las prerrogativas de las empresas francesas.

Ambos grupos dirigían sus esfuerzos en términos políticos hacia el puesto clave de la presidencia, con el objetivo de consolidar su posición a nivel político y económico. Por el lado de la aristocracia comercial, era posible encontrar los hombres de Michel Eddé que se reunían y procedían de Sursoq, ${ }^{15}$ el distrito de la capital en el corazón de la Ashrafiye cristiana, compuesto principalmente por una nobleza local decaída o la que se ha definido como la aristocracia comercial, pero que al principio del siglo había aprovechado de la situación económica del país (El-Khazen, 1991: 28-31). Por el otro lado estaba el bloque cercano a Bechara El Khoury, integrado por figuras como Michel Chiha, Henri Pharaon, principalmente hombres de negocios y banqueros o empresarios como Kettaneh y Farid Chouqueir.

Durante los años aquí en consideración se asistió a un choque particularmente cruento entre los principales representantes de estos dos bloques y grupos de interés, es decir, Bechara El Khoury y Michel Eddé. Ambos fueron candidatos al cargo de Presidente de la República en las elecciones de 1936, y fueron adversarios políticos hasta el Pacto Nacional de 1943. Por cuanto representaran dos visiones diferentes del país, los unían los parecidos intereses económicos, y el intento por parte de sus respectivos bloques de hacerse con la máquina de la modernización implantada por la potencia mandataria. 


\section{La manifestaciones populares y las huelgas de los trabajadores en los años 30}

Durante el período que sigue la crisis global del 1929 se asiste en el Líbano bajo el Mandato francés a una severa depresión económica y una fase de intensas luchas sociales, también como consecuencia del incremento de la población, la falta de empleo y el concomitante proceso de modernización. Las manifestaciones populares y de los trabajadores, en que las masas dirigieron sus quejas hacia la potencia francesa y sus políticas económicas en el Levante, fueron bastante comunes a lo largo de todo el territorio del Mandato.

El empeoramiento de la situación económica, era acompañado por una fuerte inestabilidad política, sobre todo a nivel institucional. La Constitución aprobada en 1926 fue suspendida en 1929, el Parlamento disuelto en 1932, y se creó un nuevo Parlamento temporal entre 1932 y 1934, y en el que el cargo de Presidente de la República se mantuvo en manos de Charles Debbas por otros tres años (Zisser, 2000: 17-20). En 1933 también hubo un cambio en el cargo de Alto Comisionado, donde Damien De Martel sustituyó a Auguste Henry Ponsot, cuya primera medida en 1934 fue la de restablecer las funciones del parlamento y la votación directa de los diputados.

Desde los años 20 empezaron a estallar huelgas, protestas y manifestaciones, especialmente en torno al tema de los servicios de la electricidad y la modernización: huelgas de camioneros, en las imprentas y de los empleados en la empresa del tranvía y la iluminación de Beirut, todas sociedades con capital esencialmente francés. No obstante, las autoridades francesas ya desde el 1919 empezaron a notar cierto declino en el prestigio de Francia entre los cristianos libaneses (Zamir, 1988: 87), es desde el 1927 que se registraron unas primeras, aunque aisladas quejas por parte de la burguesía en contra de la política del Mandato y unas primeras reivindicaciones para una reforma del sistema de aduanas. Sucesivamente, con el comienzo de los años 30, las movilizaciones se caracterizaron por un enfoque diferente, de las que son representativas las huelgas generales de los taxistas contra el tranvía y el alto costo de la electricidad, en la primavera de 1931, y las que al principio del 1932 criticaron el aumento del coste de la vida y tenían como objetivo la reducción de tasas e impuestos.

Los distintos decretos emitidos en esta década por el Mandato francés en materia de política económica, también provocaron protestas y reivindicaciones de los trabajadores que alcanzaron algunos importantes logros. Las protestas llevaron, después del 1935, a un ajuste de los mismos y a la emisión de decretos en los que se protegía la mano de obra nacional, se otorgaban claros y definidos derechos a los trabajadores y se regularizaban las condiciones generales de trabajo. Aunque las huelgas y protestas en estos años se centraron especialmente sobre el alto costo de la electricidad, en el bienio 1935-1936 se registraron otras huelgas más bien centradas en los derechos de las profesiones relacionadas con el sector de servicios, como las que fueron organizadas por los comerciantes, los dueños de restaurantes, los cocineros, los carniceros en Zahle o los lecheros en Beirut. 
Otra razón importante para la movilización fue la cuestión del monopolio del tabaco, como consecuencia de la decisión de la potencia mandataria de monopolizar su producción, provocando un fuerte descontento entre la población ocupada directamente en esta actividad, pero sobre todo en esa parte de la oligarquía y de la jerarquía eclesiástica cristiano maronita que tenía fuerte interés en la industria tabaquera. ${ }^{16}$

Se puede afirmar con certeza que es en esta época, al principio de los años 30 , que se asiste a un cambio sustancial en la relación entre la oligarquía cristiana y la potencia mandataria (El Solh, 2004: 34-35). Un cambio de actitud debido al fracaso económico y la concomitante crisis financiera, acompañado por la siempre presente crítica contra las empresas concesionarias, que excluían, en principio, los libaneses de los puestos de funcionarios de alto rango dentro de estas mismas empresas. Desde este momento, aunque aún en voz baja, una parte de la base real de las protestas empezaron a ser aquellas élites que querían disfrutar plenamente de las potencialidades económicas de su país y tener en sus manos el proceso de modernización. Las protestas en estos casos empezaron a adquirir una más evidente reivindicación económica y nacionalista, lo que representaba un cambio en comparación con la etapa anterior. Al mismo tiempo, sentaba las bases para aquel consenso antifrancés que se generalizaría por primera vez en estos años y llegaría a su cúspide en 1943.

Es necesario también señalar que los movimientos de protesta que irrumpieron en los primeros años 30 fueron más bien fruto de la espontaneidad de la población que de una presencia fuerte de los sindicatos sobre el territorio o una organización planificada desde arriba (Couland, 1970: 186). La espontaneidad de las movilizaciones y la falta de una organización bien definida representaron una excelente oportunidad por parte de la oligarquía económica y financiera local para vehicular este malcontento popular y favorecer sus personales intereses políticos y económicos en contra del Mandato y los adversarios políticos.

\section{La carrera presidencial, las críticas al Mandato y las movilizaciones populares en la prensa francófona en el período 1934-1936}

$\mathrm{Al}$ comienzo de los años 30 las movilizaciones se hacen más relevantes y frecuentes, empiezan a configurarse como una forma moderna de protesta contra las políticas económicas del Mandato francés, y donde los bloques de la oligarquía cristiana jugaron un rol importante.

En el primer período de movilizaciones que va desde 1918 hasta 1930, la prensa francófona de la época no puso demasiado énfasis en las demandas de los manifestantes, en línea con la visión de la oligarquía detrás del periódico francófono L'Orient, que respaldaba en esta década la potencia mandataria. La prensa francófona demostró ser mucho más activa e involucrada en la cobertura de las protestas y las huelgas en el período que va desde el 1934 hasta el 1936. Los periódicos se centraron en diferentes temas que se presentaron reiteradamente en estos años en sus páginas, y que 
de fondo expresaban una más o menos directa crítica al Mandato. Los periódicos de habla francesa también empezaron a enfrentarse el uno al otro, develando al público los intereses del adversario político, siempre con la mira a la elección del Presidente de la República programada para enero de 1936.

No obstante los ataques recíprocos, comunes en la prensa libanesa de la época entre los diferentes actores políticos (Ayalon, 1995: 86), lo que implícitamente une a las diferentes componentes de la oligarquía cristiana de la época es, aunque en diferente escalas, el carácter antimandatario que expresaron ambos bloques desde las páginas de sus periódicos de referencia. Los principales temas de contraste, tal como la cuestión del monopolio del tabaco, la gestión de la compañía del agua, la política económica del Alto Comisionado, y las cuestiones relativas al poder económico y político, o sea las reivindicaciones nacionalistas y antifrancesas, se unieron en estos años en las columnas de los dos periódicos, no obstante los dos bloques tuvieran diferentes visiones sobre el futuro Líbano.

La cuestión de las huelgas y las protestas de estos años fueron telón de fondo y vehículo de una lucha más definida por hacerse con la máquina de la modernización y el control de los recursos económicos, que hasta el momento se encontraban casi completamente en manos de los franceses. La elección del Presidente de la República aparecía entonces como un paso esencial para alcanzar el poder nacional y la herencia de los franceses en un futuro Estado libanés independiente.

Es posible, por estas diferentes razones, entender las posiciones de fondos de los bloques de la oligarquía cristiano libanesa respecto al Mandato a través del análisis de los contenidos de estos periódicos. A través de algunos artículos de fondo y editoriales, ambos periódicos sugieren repetidamente su apoyo a las posiciones y demandas en relación con huelgas y movilizaciones, aunque siguiendo sus particulares intereses y manteniendo una elevado nivel de competición con el adversario político. Por ejemplo, las demandas de los taxistas y los conductores del transporte público, que fueron a la base del descontento popular en estos años, no encontraron particular espacio en los periódicos. La crítica hacia este grupo de huelguistas se justificaba en los periódicos con el temor de un bloque de la industria de servicios durante la temporada de verano, y con la posible consecuencia de una pérdida económica importante por el sector terciario en Líbano, en que ambos bloques tenían intereses. En abril de 1935, L'Orient y más tarde también Le Jour publicaron una serie de editoriales críticos respecto a estas huelgas, aprovechando para culpar al otro bloque de fomentar las movilizaciones. El editorial del 3 de abril de Le Jour las considera como "manifestations qui porterait un tort considérable aux intérêts du pays". ${ }^{17}$

Ambos periódicos intentan destacar con más vigor las demandas y exigencias de los grupos más cercanos a sus intereses, como es el caso de las protestas de los comerciantes. El periódico Le Jour apoya en varias ocasiones la formación de sindicatos y la reglamentación del trabajo, y parece estar más cerca a los asalariados que hacen parte de un mercado industrial nacional, como los artesanos de la industria y la agricultura, y los empleados del comercio. ${ }^{18}$ El periódico cercano a El Khoury apoya 
en sus artículos del 22 y 23 de mayo de 1935 los reclamos relativos a un cambio en los aranceles de las aduanas, una nueva repartición de los intérets communs, la participación local en las sociedades concesionarias y la revisión de los monopolios y las franquicias de los comerciantes en huelga. Un respaldo que estaba en línea con uno de los objetivos de la burguesía que hacía referencia a Bechara El Khoury, que se proponía estabilizar su poder económico creando un mercado interno fuerte y sostenible. L'Orient también, el 24 de mayo de 1935, defiende la huelga de los comerciantes, sugiriendo a los manifestantes que incluyan en sus reivindicaciones un cambio en la política económica del Mandato y en los impuestos sobre los ingresos de los comerciantes, definiéndolos como "braves gens" que luchan contra impuestos injustos.

Pero lo que más relevancia tuvo en las páginas de L'Orient fue la reivindicación para la reforma del sistema fiscal y los aranceles. La reducción de los costes de aduanas habría sin duda servido a los intereses de empresarios e industriales libaneses de ambos bloques, que en este momento histórico exigían a la potencia mandataria una nueva política económica y un área de comercio más liberalizada. L'Orient en este caso instala una verdadera campaña para la reducción de los costes de aduana, sólo en parte y con menos vehemencia apoyada en las columnas de Le Jour. La cuestión de la reducción de los costes de aduana ensayada por los comerciantes libaneses, aunque de formas y con objetivos diferentes, suponía así un ataque contra la política económica del Mandato francés. ${ }^{19}$ De la misma forma, y en nombre de la reforma del sistema fiscal y un cambio en la política económica del Mandato, L'Orient respaldaba también las protestas de los carniceros en la ciudad a mayoría cristiana de Zahle al final de enero del 1935. ${ }^{20}$

Ambos periódicos siguieron muy de cerca la polémica cuestión del monopolio del tabaco y la confrontación directa entre el Patriarca de la Iglesia Maronita Arida y la potencia mandataria francesa. ${ }^{21}$ En enero de 1935, Le Jour publicó una serie de editoriales sobre el tema del monopolio del tabaco y puso sobre la mesa de discusión la idea de conformar una comisión para estudiar la forma más oportuna para la explotación del monopolio del tabaco. El mismo Le Jour el siguiente mes publicó una serie de declaraciones del patriarca Arida que reclamaban dignidad para los libaneses, la necesidad que ellos mismos intervinieran en sus asuntos, participaran en el poder y que volviera en funcionamiento la Constitución suspendida, lo que coincidía con las reivindicaciones del Bloque Constitucional de El Khoury. ${ }^{22}$ El mismo Chiha aprovechó de la cuestión para publicar casi a diario una serie de artículos y editoriales desde el noviembre del 1934 hasta febrero del 1935, donde pedía explícitamente un monopolio del Estado. L'Orient tuvo una posición más distante y crítica respecto a la cuestión del monopolio del tabaco y la posición del Patriarca. Este periódico, el día 6 de febrero de 1935, expresa con un explícito editorial titulado "La dangereuse aventure" su posición respecto a las críticas del Patriarca sobre el monopolio del tabaco y su posición abiertamente antimandataria. El periódico dedica una editorial y un artículo de opinión en enero de 1935 en los que se describen la cuestión y en los que ofrecen la oportunidad de atacar tanto al campo político opuesto como al Mandato, pidiendo 
que se dirigieran las quejas a los franceses para que se cambiaran las recetas de la aduana. Mientras en un primer momento, el 18 de enero de 1935, L'Orient se dedica simplemente a una explicación de la cuestión en la que se encuentra únicamente un breve ataque al grupo de Bechara El Khoury, solo después de la proclamación del mismo monopolio, el periódico el 23 de febrero, aprovecha de algunas protestas de los estudiantes para dirigir sus críticas hacia el Mandato, sobre todo por el tema de las aduanas y concede un espacio al Patriarca con una entrevista publicada el 24 de marzo de 1935. El ataque al Mandato es presente en ambos grupos y periódicos, pero cada uno siguiendo sus peculiares intereses económicos y agenda política.

En estos años comienza a verse en los periódicos un claro y público apoyo a las manifestaciones con carácter antifrancés. Las editoriales de ambos periódicos tienen a menudo un corte antimandatario, mezclando un silencioso apoyo a las protestas con la crítica hacia la política económica del Alto Comisionado De Martel, invocando también directamente, sin esconderse detrás de manifestaciones y huelgas, una reforma del sistema tributario y la reducción de los costes de aduana. El 23 octubre del 1934, Le Jour publica una carta abierta al Alto Comisionado para pedir una nueva política económica y un mes después, el 24 de noviembre, critica abiertamente su política económica que afecta principalmente a los comerciantes. L'Orient, en el editorial del 10 de enero de 1935 pide la independencia para el país de los cedros y auspicia la creación de un movimiento de masas que la reivindique en las calles, y al mismo tiempo invoca un despertar nacional antiaristocrático, antiintelectual y anticonservador, dirigido directamente en contra de los adversarios políticos:

le jour au ce peuple, qu'ils invoquent et n'évoquent pas, s'usera de revendiquer ses droits, où ces peuple prendra conscience de la réalité de sa face, c'est a eux c'est aux élites, c'est aux bourgeois possédant qu'ils s'attaquera d'abord: et c'est le poète et le banquier que subiront la première vague d'assaut.

L'Orient presenta en ocasiones específicas artículos y columnas con cortes particularmente populistas, en donde se mezclan proclamas de nacionalismos con reivindicaciones populares, desafiando el control del Parlamento por parte de los franceses y como arma política contra el bloque de El Khoury. El 25 de enero del 1935 L'Orient pide la emancipación de las masas, un nuevo nacionalismo "más nacional" y una transformación de la política económica del mandato. Mientras el 26 de enero del 1935 el periódico rechaza completamente la legitimidad del parlamento bajo Mandato francés y declara que "quand le fellah entrera a la Chambre, et que le salué $y$ rencontrera son patron, L'Orient se fera parlementariste. Mais pas avant!'. ${ }^{23}$

En este ámbito se mezclan tanto las proclamas nacionalistas, antifrancesas, y a favor de una nueva política económica, como los ataques contra el opositor político en la carrera hacia la presidencia de la República. ${ }^{24}$ Estos ataques se deben entender aquí come una forma de concientización por parte de los dos bloques de las potencialidades de los medios de comunicación de masa, en particular modo de la prensa escrita, como herramienta fundamental en el ámbito de la batalla política. No es casualidad que el periódico Le Jour empiece sus primeras semanas de vida con una campaña de ataques contra L'Orient y Eddé, acusándolo de nepotismo y corrupción, 
y fijándose específicamente en el mal funcionamiento de la compañía de agua, por el hecho de que Eddé había participado en su junta directiva. En este caso y en varios artículos y editoriales, se presenta Eddé como cercano a las políticas económicas del Mandato y como una figura que se quiere aprovechar del monopolio del tabaco. ${ }^{25}$ El mismo Chiha se encarga en esta fase inicial con varias editoriales de liderar el ataque contra Eddé y el grupo de L'Orient. El 16 de agosto del 1934 el periódico acusa Eddé de haber manipulado el resultado de una serie de procesos en los que se encontraba involucrados: "Histoire de brigands...un exploit d'Emile Eddé" titula Le Jour. El 25 de agosto del 1934 el periódico publica un artículo titulado"Emile Eddé et les mensognes"; y el 28 de septiembre del 1934 otro con el título "Emile Eddé et L'Orient continuent'. En todas estas editoriales hay críticas y acusaciones directas a Michel Eddé.

También L'Orient ataca directamente Bechara El Khoury en el agosto de 1934 por haber elegido a Sami Khuri como consejero de Justicia y en sus editoriales que van desde el 24 de agosto hasta el 28 , ataca a la facción opuesta y sus medios de comunicación, que define como la "presse des maffieux". Lo que esconden estos ataques y confrontaciones directas por parte de los dos periódicos es la necesidad de definir con claridad la posición política y económica de cada bloque y alejarse del otro, con vista a la carrera presidencial.

\section{Conclusión}

El bloque de Michel Eddé logró finalmente acceder a la Presidencia de la República en las elecciones de 1936, pero fue la oligarquía reunida alrededor de El Khoury la verdadera ganadora a largo plazo de la disputa interna a la comunidad cristiana. La visión de Líbano que surgirá con la real independencia del país fue la que promovió El Khoury, elegido Presidente de la República en 1943, y principal artífice del Pacto Nacional junto con el musulmán Riad el Solh. Su bloque, que se formó en los años aquí analizados, consiguió disfrutar así de los privilegios económicos que suponía la cercanía a la presidencia. De hecho, en los primeros años de presidencia por parte de El Khoury, hubo una total unión de intereses entre la presidencia y el círculo de hombres de negocios que lo apoyaron, y esta oligarquía utilizó la cercanía a la autoridad política para reformar por completo la economía libanesa según sus propios intereses personales (Traboulsi, 2007: 115-117).

La diferencia principal entre los dos bloques que contendieron la presidencia en 1936, y que siguieron su disputa en los años siguientes, se encuentra en la proyección de la oligarquía reunida alrededor de El Khoury de poner las bases para un proyecto que produjera una estabilidad de su poder económico a largo plazo. El proyecto del bloque de El Khoury entendía la necesidad de expandir su propia influencia a nivel político y económico más allá de la cercanía a los franceses, así como seguía a grandes líneas desarrollando el bloque alrededor de Eddé, con el objetivo de alcanzar una 
sostenibilidad a largo plazo (Gates, 1989: 15-34). El bloque de El Khoury empezó a construir las bases de este proyecto en el momento en que se constituyó el Bloque Constitucional, y en el momento en que se fundó en 1934 el periódico Le Jour, que le permitió consolidar el grupo, alejarse clara y públicamente del bloque de Eddé y contrastar la posición del adversario que salía de las páginas de L'Orient.

El bloque de Eddé se enfrentaba a las políticas económicas del Mandato y apoyaba las reivindicaciones de las protestas para mejorar las ventajas económicas de las que su grupo ya disfrutaba, aunque manteniendo vivo interés en la posibilidad de manejar directamente la economía nacional. Pero, a través del análisis de la literatura existente y la prensa cercana a los dos bloques, la consideración más relevante es que la oligarquía alrededor de El Khoury tenía un proyecto mejor estructurado y a más largo plazo.

La época de los años 30 es por estas razones de particular importancia en la región del Levante bajo el Mandato francés, tanto a nivel político como económico, y tanto a corto como a largo plazo. A nivel político se asistió a un cambio en la posición de las oligarquías cristianas respecto al Mandato, y se alcanzó un acercamiento entre las diferentes visiones del futuro Líbano, tanto por parte de las elites cristianas como musulmanas, y que llevó al Pacto nacional de 1943. A nivel económico, la situación pareció madura, por una parte,las elites cristianas por hacerse con la máquina de la modernización implantada por la potencia francesa desde su llegada a la región, y tomar en sus manos directamente el control de la economía y del mercado nacional.

El pasaje hacia una fase de capitalismo industrial, junto con las consecuencias de la depresión global del 1929 y las inversiones de los emigrantes extranjeros con capitales, crearon una coyuntura en que los intereses de las elites se vieron fuertemente afectados por el hecho que la potencia francesa aún mantenía el control de la modernización del país. Estas condiciones llevaron a un enfrentamiento entre dos bloques opuestos dentro de la comunidad cristiana, pero con intereses parecidos en términos económicos. En el ámbito de esta disputa política, la lucha y los ataques contra los franceses parecen ser una herramienta más en manos de estas oligarquías cristianas para conseguir sus objetivos políticos e intereses económicos.

Al mismo tiempo, a través del análisis de la joven prensa francófona libanesa, resulta evidente como los medios de comunicación empezaron a adquirir relevancia como herramientas para alcanzar unos objetivos políticos, y como las oligarquías entendieron el potencial de los mismos como vehículo para divulgar su agenda política, en este caso representada por las críticas hacia las políticas económicas del Mandato francés y hacia los adversarios políticos.

El análisis de la prensa en relación con las manifestaciones de descontento popular revela como las elites cercanas tanto a L'Orient como a Le Jour utilizaron todos estos acontecimientos para dar un cambio radical en sus posiciones hacia las políticas económicas del Mandato y con el fin de obtener el control total de la economía y la política nacional. ${ }^{26} \mathrm{Y}$ es sobre todo a partir del final de los años $20 \mathrm{y}$ principio de los 30 que esta burguesía comienza a lanzar sus ataques de una manera más directa 
contra la política mandataria, pidiendo la reducción de los impuestos y los costes de aduana y una nueva política económica que favoreciera sus intereses. En el período aquí analizado, entre el 1934 y el 1936, el nacionalismo de las oligarquías cristianas de Beirut, se unió en términos de metas a largo plazo y representó el deseo de aumentar su participación en la vida pública, política y económica.

Como consecuencia directa de las presiones populares y el respaldado de la oligarquía local, en el noviembre de 1936 se ratificó el tratado franco libanés, en que se garantizaba la independencia futura de Líbano y su soberanía, y en el 1937 se empezó una negociación entre los delegados sirios y libaneses para la transferencia de los intereses comunes. Estas medidas representaron las últimas etapas de las negociaciones antes de alcanzar en 1943 la asignación de los intereses comunes en las manos de los Estados independientes.

Finalmente, la importancia de esta fase histórica se debe también a la constatación del surgimiento de un principio de nacionalismo compartido por diferentes actores, en que se unen las componentes populares, las categorías profesionales y las oligarquías, aunque todos persiguiendo sus intereses específicos. ${ }^{27}$ Estas movilizaciones fueron capaces de formar una especie de proto-nacionalismo que en la historiografía de la época está casi completamente olvidado.

Es por estas razones que el presente artículo quiso investigar de forma conjunta los componentes de este movimiento proto-nacionalista que nació casi espontáneamente por reivindicaciones de las elites y descontento popular, y donde empiezan a verse los primeros síntomas de una movilización auténticamente libanés sin relación con el nacionalismo árabe y sirio.$^{28}$ Es de hecho desde los eventos de esta época y este proto-nacionalismo que se crearon las condiciones para un acercamiento entre las elites musulmanas y cristianas, con el objetivo de moldear la idea del Estado libanés que saldrá con el Pacto Nacional y sigue siendo a la base de la estructura del sistema político actual.

\section{Referencias bibliográficas}

AL-SALEH, M. A. (2002). "Introduction de partie. Les aspects économiques généraux de la relation mandataire France, Syrie et Liban, 1918-1946", en Nadine Méouchy (ed.), France, Syrie et Liban 1918-1946: Les ambigüités et les dynamiques de la relation mandataire, Damas: Presses de l'Ifpo, pp. 197-210 [http:// books.openedition.org/ifpo/3182, consultado el 18 de julio, 2014.]

AYALON, A. (1995). The Press in the Arab Middle East: A History, New York, Oxford: Oxford University Press.

CHIDIAC, E. (2002). "Les intérêts communs syro-libanais (1920-1950)", en Nadine Méouchy (ed.), France, Syrie et Liban 1918-1946: Les ambigüités et les dynamiques de la relation mandataire, Damas: Presses de l'Ifpo, pp. 259-271 [http:// books.openedition.org/ifpo/3190, consultado el 18 de julio, 2014.] 
CHIHA, M. (1964). Politique intérieure, Beyrouth, Éditions du Trident.

COULAND, J. (1970). Le mouvement syndical au Liban, 1919-1946: son évolution pendant le mandat français de l'occupation à l'évacuation et au Code du travail, Paris, Editions sociales.

DAHER, M. (2000). L'histoire socio-politique de la République libanaise sous mandat français : 1926-43, Paris, Thèse de Doctorat, Université Paris I.

EDDE', C. (2004). "La mobilisation "populaire" à Beyrouth à l'époque du Mandat (1918-43): l'apprentissage progressif de la participation", en Nadine Méouchy et Peter Sluglett (eds.), The British and French Mandate in Comparative Perspectives, Leiden, Brill, pp. 623-648.

EL-KHAZEN, F. (1991). The Communal Pact of National Identities: The Making and Politics of the 1943 National Pact, Oxford, U.K., Centre for Lebanese Studies.

EL SOLH, R. (2004). Lebanon and Arabism: National Identity and State Formation, London: I.B. Tauris, The Centre for Lebanese Studies, Oxford.

FAHRENTHOLD, S. (2013). "Transnational Modes and Media: The Syrian Press in the Mahjar and Emigrant Activism during World War I", Mashriq \& Mahjar: Journal of Middle East Migration Studies, 1, (Spring 2013): 32-57.

FIRRO, K. (2003). Inventing Lebanon: Nationalism and the State under the Mandate, London, I. B. Tauris.

GATES, C. (1989). The Merchant Republic of Lebanon: Rise of an Open Economy, Oxford and New York: Centre for Lebanese Studies and I.B. Tauris.

GHORAYEB, M. (2000). La transformation des structures urbaines de Beyrouth pendant le Mandat français, Paris, Thèse de doctorat en urbanisme et aménagement de la Université Paris VIII, Institut français d'urbanisme.

KAUFMAN, A. (2004). “"Tell Us Our History': Charles Corm, Mount Lebanon and Lebanese Nationalism", Middle Eastern Studies, Vol. 40, No. 3 (May, 2004), pp. $1-28$.

KEDOURIE, E. (1974). Arabic Political Memoirs and Other Studies, Oxon, Franck Cass.

KHOURY, G. D. (2002). "Introduction de partie. Les conditions d'instauration du Mandat français au Proche Orient après la Première guerre mondiale", en Nadine Méouchy (ed.), France, Syrie et Liban 1918-1946: Les ambigüités et les dynamiques de la relation mandataire, Damas: Presses de l'Ifpo, pp. $75-89$ [http://books. openedition.org/ifpo/3169, consultado el 18 de julio, 2014.]

MEOUCHY, N. (2002). "La presse de Syrie et du Liban entre les deux guerres (1918-1939)", Revue des mondes musulmans et de la Méditerranée, $\mathrm{n}^{\circ}$ 95-96-9798, Aix-en-Provence, p. 55-70.

MIZRAHI, J. (2002). La France et sa politique de mandat en Syrie et au Liban (19201939), en Nadine Méouchy (ed.), France, Syrie et Liban 1918-1946: Les ambigüités et les dynamiques de la relation mandataire, Damas: Presses de l'Ifpo, pp. 35-71, [http://books.openedition.org/ifpo/3166, consultado el 18 de julio, 2014.]

PACHECO PANIAGUA, J. A. (2006). "La prensa árabe en Chile: Sueños y realidades árabes en un mundo nuevo", Miscelánea de Estudios Árabes y Hebráicos, Vol. 55, pp. 277-322. 
SALIBI, K. (1989). A House of Many Mansions: The History of Lebanon Reconsidered, London: I.B. Tauris.

TRABOULSI, F. (2007). A History of Modern Lebanon, London-Ann Arbor, Mi: Pluto Press.

TRABOULSI F. (2014). Social Classes and Political Power in Lebanon, Beirut, Heinrich Boll Foundation.

ZAMIR, M. (1978). "Emile Eddé and the Territorial Integrity of Lebanon", Middle Eastern Studies, Vol. 14, No. 2 (May 1978), pp. 232-235.

ZAMIR, M. (1988). The Formation of Modern Lebanon, Ithaca, NY, Cornell University Press, 1988.

ZISSER, E. (2000). Lebanon, The Challenge of Independence, New York: I.B. Tauris, 2000.

ZISSER, E. (1994). "The Downfall of the Khuri Administration: A Dubious Revolution”, Middle Eastern Studies, Vol. 30, No. 3 (Jul., 1994), pp. 486-511.

\section{Notas}

1 Francia hará un intento de dividir el territorio bajo su control en pequeños Estados con fuertes bases confesionales. El proyecto francés no tendrá éxito a largo plazo por la presencia de una fuerte componente nacionalista árabe en toda la región del Levante que auspiciaba una gran patria árabe.

2 Los que se propusieron conformar en Líbano una economía con base principalmente en los servicios, fueron llamados con el apodo los New Phoenicians, y eran principalmente intelectuales cristianos maronitas. Es curioso que entre las figuras que se identificaron con esta postura se encuentran unos cuantos que sucesivamente se contenderán el poder con el objetivo de excluir los franceses tanto a nivel político como económico. Véase Traboulsi, pp. 91-97.

3 Es necesario destacar la profunda diversidad interna de la comunidad cristiana, que se explica solo en parte a través del prisma confesional, sino más bien con los intereses particulares de algunos de sus miembros. La comunidad maronita siempre tuvo una preponderante posición aislacionista, como es el ejemplo de Eddé y el Partido de las Falanges Libanesas establecido por Pierre Gemayel en 1936. Las otras principales comunidades cristianas, tales como los griegos-ortodoxos y los griegos católicos, siempre tuvieron una posición en términos nacionalistas mucho más incluyente hacia el mundo árabe y se afiliaron a partidos políticos laicistas. La configuración cada vez más marcada en esta época del sistema confesional llevará a la casi exclusión de estos partidos en la siguiente repartición del poder sobre base confesional. Un ejemplo de esto es el caso de Antun Saade y de su partido, el Partido Social Nacionalista Sirio (PSNS), fundado en 1932. Saade, con su variante de nacionalismo pan-sirio, representaba el punto intermedio entre el aislacionismo maronita y el nacionalismo árabe que llegaron a un acercamiento con el Pacto Nacional en 1943, Saade, después de un intento de golpe de estado, será ejecutado en 1949. Véase Traboulsi, p. 112.

4 Ambas figuras precedentemente hicieron parte del movimiento político hizb al-taraqqi, el Partido del Progreso, junto con Marquis de Freij, Yusuf al-Jumayyil y Michel Chiha entre otros. Véase Elie Kedourie, Arabic Political Memoirs and Other Studies, Oxon, Franck Cass, 1974, p. 51; La Constitución del 1926 se tiene que interpretar como la consecuencia de una presión por parte de los cristianos maronitas por una mayor autonomía e independencia de los franceses. Vease Farid El-Khazen, The Communal Pact of National Identities: The Making and Politics of the 1943 National Pact, Oxford, U.K., Centre for Lebanese Studies, 1991, p.8. 
5 El Khoury también al principio de su carrera fue bastante cercano a Francia y al Mandato y por eso también fue elegido primer ministro entre el 1927 y el 1929. El cambio en su posición se dio en los años 30. Véase Eyal Zisser, "The Downfall of the Khuri Administration: A Dubious Revolution", Middle Eastern Studies, Vol. 30, No. 3 (Jul., 1994), pp. 486-511.

6 Según Zamir, Eddé, a la luz de esta nueva situación, iba considerando la posibilidad de promover el establecimiento de un pequeño Líbano sin que se incluyeran las regiones musulmanas. El autor considera que nunca se hicieron publicas estas declaraciones, especialmente porque Eddé conocía el total rechazo por un pequeño Líbano por parte de la mayoría de los cristianos. Véase Zamir, op. Cit., 1978, pp. 233-234.

7 Charles Corm fue uno de los que en aquellos años inventó lo que se definió como el nuevo modelo fenicio, que veía el Líbano basarse principalmente en una economía de servicios. La idea fenicia no era característica de solo un bloque político, pero en general se puede decir que era compartida por diferentes grupos con diferentes agendas políticas y económicas. Véase Asher Kaufman, "Tell Us Our History': Charles Corm, Mount Lebanon and Lebanese Nationalism", Middle Eastern Studies, Vol. 40, No. 3 (May, 2004), pp. 1-28.

8 La familia Chiha, de la comunidad católica romana, muy de cerca emparentada con los Pharaon, era el perfecto ejemplo de aquella burguesía financiera y comercial que surgió en Líbano al final del siglo XIX, y que después de invertir en el capitalismo mercantil y el mercado de las exportaciones, movió sus intereses en el establecimiento de una industria nacional, estableciendo una sociedad financiera y comercial. Estas nuevas figuras se pusieron a competir con la ya presente aristocracia mercantil, lo que será a la base del choque directo dentro de la comunidad cristiana. Véase Traboulsi, op. Cit., p. 59. Para una visión general del pensamiento de Chiha sobre Líbano, véase Michel Chiha, Politique intérieure, Beyrouth, Éditions du Trident, 1964.

9 Charles Helou, abogado y emprendedor cercano a Chiha, fue director de Le Jour por varios años y en los años 60 fue elegido como Presidente de la República.

10 Michel Chiha había estado cerca a la posición de Eddé, pero desde los años 30 empezó a distanciarse. La fundación del periódico hace parte de este intento de proponer una visión nueva de Líbano por parte de otro bloque de la oligarquía cristiana. Los dos periódicos se unirán sucesivamente en un solo periódico en el septiembre de 1970.

11 Meir Zamir, Lebanon's Quest: The Road to Statehood, 1926-1939, London: I.B. Tauris, 1997, pp. 32-37. Vease los editoriales de Le Jour de los días 16 y 17 de abril de 1935.

12 Los numerosos periódicos en lengua árabe, así como otros menores de habla francesa, no se consideran en este articulo, aunque tuvieron particular importancia en el proceso para alcanzar la independencia y transmitir las ideas nacionalistas. Se considera que estos en su mayoría eran más cercanos a las reivindicaciones de las elites musulmanas, que optaban por un nacionalismo "árabe" incluyente y no consideraban aún claramente la posibilidad de un Líbano independiente separado de la Siria. Véase El-Khazen, pp. 10-11.

13 Había por ejemplo relaciones familiares entre El Khoury y Chiha, y entre El Khoury y Pharaon. Chiha era por parte de madre miembro de la familia Pharaon. Eddé al contrario tenia relaciones familiares con los Sursoq. Es imposible definir perfectamente estos dos bloques según unos confines ideológicos claros o específicos sectores económicos de interés, porque en la mayoría de los casos las alianzas eran de tipo matrimonial y reflejaban principalmente los intereses económicos de un clan respecto a otro Tampoco es posible definir las posiciones sobre los diferentes nacionalismos unicamente a través de una referencia holística a las comunidades confesionales. Véase Kamal Salibi, A House of Many Mansions: The History of Lebanon Reconsidered, London: I.B. Tauris, 1989, pp. 54-55.

14 Respecto al termino sugerido por Daher de "burguesía de compradores" se prefiere utilizar aquí lo de aristocracia comercial o mercantil, como sugerido por Traboulsi, aunque los dos términos se refieran al mismo grupo, los de Eddé. 
15 La Sursoq era una familia de confesión griego-ortodoxa entre las más ricas y prestigiosa en la época entre el siglo XIX y el XX. Toma el nombre de la familia el barrio donde ellos residían. Los Sursoq eran los verdaderos representantes de la que hemos definido la aristocracia mercantil. Véase, Daher, op. Cit., pp. 614-633.

16El 30 de enero de 1935, a través del decreto ${ }^{\circ}$ 16/LR, se concedió el monopolio del tabaco a una sociedad francés por 25 años. Véase Kais Firro, Inventing Lebanon: Nationalism and the State under the Mandate, London, I. B. Tauris, 2003, p. 135; Daher, op. Cit., pp. 489-493. El descontento hacia los franceses por parte de la Iglesia maronita ya se podía ver en 1933 cuando el Arzobispo maronita de Beirut, Ignatius Mubarak, organizó una serie de protestas en contra de los franceses. Véase El-Khazen, op. Cit., pp. 8-10; Mizrahi, op. Cit., pp. 35-71.

17No obstante, como afirma Traboulsi, hubiera intereses por parte de los Kettaneh, cercanos al periódico, de privatizar la empresa de transporte, Le Jour no parecía tan cercano a esta categoría de manifestantes. Véase Traboulsi, op. Cit., 264 n.15.

18El 20 de septiembre del 1934 y el 4 diciembre del 1934 por ejemplo Le Jour publica una defensa primero de los asalariados y una carta de los empleados del comercio al Alto Comisionado para exigir una reglamentación del trabajo. En ambos casos se pide la creación de sindicatos de categoría.

19Esta posición que pedía bajar las tarifas de aduana y acabar con los privilegios de las empresas extranjeras en cualquier ámbito queda bien explicitada en un articulo del 22 de febrero del 1934 en Le Jour y en el editorial de L'Orient del 8 de marzo de 1935, con el titulo "Discours a un francais".

20 El 31 de enero el periódico declara su apoyo total a los pequeños contribuyentes, hasta auspiciar su rebelión contra tal injusticia.

21 Se puede opinar que el Patriarca Arida y la Iglesia Maronita tuvieran particulares intereses económicos en la cuestión del monopolio del tabaco y respecto a la posición hegemónica de la potencia mandataria en la política económica libanesa. El mismo Arida era presidente honorario de la "Qadicha”, una sociedad anónima por la electricidad del Norte de Líbano, establecida en 1924, y estaba directamente en posesión de otras fabricas de tejidos en la zona alrededor de Trípoli. Véase Daher, op. Cit., pp. 523-563.

22 Sobre la cuestión del monopolio del tabaco en el periódico Le Jour, se vean en particular modo los artículos publicados el 7, el 12 y el 29 de enero de 1935, así como desde el 5 hasta el 8 de febrero el periódico le dio cobertura diaria al tema. El 17 de febrero Le Jour da espacio en sus paginas a una carta de critica sobre el monopolio del tabaco por parte del arzobispo de Beirut, Mubarak. El Khoury y Arida se aliaron políticamente y abiertamente al principio del 1940.

23 No estamos de acuerdo evidentemente con Daher que considera que el bloque de El Khoury era lo que invitaba las masas de los obreros y los campesinos a levantarse en contra del Mandato. Véase Daher, op. Cit., pp. 614-633.

24Hay un ataque a L'Orient por parte del periódico di El Khoury por no apoyar las protestas de los comerciantes y los estudiantes el 23 de febrero del 1935. Como mencionado, L'Orient en aquellos días pedía a los huelguistas mover sus quejas no contra el monopolio del tabaco, pero mas bien contra los aranceles.

25 Se vea el articulo de Le Jour del 14 de agosto del 1934, a pocos días de la abertura del periódico.

26 También se puede pensar que haya jugado un rol importante en la disputa entre los dos bloques, e influenciado el cambio en las posiciones de los mismos, las características y orientaciones de los diferentes Alto Comisionados que se intercambiaron en aquellos años. Por un lado Henry Ponsot, que estuvo en el cargo desde el 1926 hasta el 1933 y tenía el objetivo de desarrollar una política económica proteccionista, en contra de los sectores del capitalismo urbano beirutì y que tenia bastante cerca Emile Eddé. Damien De Martel, su sucesor, se encargó al contrario de eliminar las políticas 
de su predecesor. Esta medida favoreció en parte Eddé debido a las resistencias de los movimientos sirios a reconocer un Líbano independiente. Véase Mizrahi, op. Cit., pp. 35-71.

27 Este tipo de nacionalismo se diferencia de los anteriores por ser precursor de lo que se consolidó mas tarde como el nacionalismo a la base del Pacto Nacional del 1943, con una unión transconfesional y de diferentes componentes de la sociedad.

28 Es importante destacar que en los años 30 empezaron a darse las condiciones también dentro de la comunidad musulmana, y entre sus intelectuales, para un acercamiento a una visión más incluyente del futuro Líbano. Véase El Khazen, op. Cit., pp. 7-9. 